\title{
Inequality, Military Veteran Transitions, and Beyond: Compensatory Control Theory and Its Application to Real World Social Justice Problems
}

\author{
Aaron C. Kay ${ }^{1} \cdot$ W. Connor Gibbs ${ }^{2}$
}

Accepted: 18 December 2021 / Published online: 29 January 2022

(c) The Author(s), under exclusive licence to Springer Science+Business Media, LLC, part of Springer Nature 2022

Conducting social justice research as a psychological scientist can sometimes be a confusing pursuit. Should your ideas and research projects tackle issues of social justice head on, or should you instead focus on more basic psychological processes, ones that give rise to and help explain the kinds of issues social justice researchers think about? While these two paths are inextricably linked, the latter route can at times feel removed from the issues that might have sparked your interest in the field to begin with: A student who entered the field because of their experience with racism might find themselves years later researching the cognitive contours of categorization processes; or someone who was driven to their $\mathrm{PhD}$ because they wanted to reduce extremism might, before they know it, be instead studying the neurological basis of cognitive consistency.

Of course, much of the greatest research and theory that has tackled issues of social justice head on has drawn on basic psychological processes - ones that, when originally developed, probably seemed to have little to do with the justice issues they are being applied to. For example, Lerner's belief in a just world (Lerner, 1980), which has given rise to decades of research on victim-derogation, is deeply rooted in basic theories of cognitive development. Likewise, research on stereotype threat (Steele, 1997) and its reduction in educational settings (e.g., Sherman et al., 2013) have roots in Lewinian notions of subjective construal, channel factors, and the interplay of motivational and cognitive processes. But there is a distinct difference between drawing on basic ideas to inform social justice research and actually spending the time doing that research.

Aaron C. Kay

aaron.kay@duke.edu

W. Connor Gibbs

wcgibbs@ucsb.edu

1 Fuqua School of Business and Department of Psychology and Neuroscience, Duke University, Durham, USA

2 Department of Psychological and Brain Sciences, University of California, Santa Barbara, USA 
For this special issue of Social Justice Research, we would like to use this space to reflect on the tension between conducting basic research and applied research in the pursuit of social justice. Or, more specifically, on how developing and working on social scientific theory can resolve this tension, affording researchers the opportunity to build a line of work that can shift between more and less applied research questions while remaining programmatic and thematic. By tracing the trajectory of compensatory control theory (CCT; Kay et al., 2008) - from its initial investigations to a current initiative aimed at understanding military to civilian transitions-we hope to illustrate how developing theory can be a fruitful way for researchers to bridge their basic and applied interests.

Compensatory control theory was inspired by a social justice theory, to be sure, but the initial questions it sought to address were more basic and mechanistic than applied or of obvious practical import. Over time, though, as the basic tenets of the theory were supported, the research contexts in which CCT was tested and the questions it was used to help answer morphed: shifting from more intellectual and academic to socially relevant and consequential.

Inspired by system justification theory (Jost \& Banaji, 1994), compensatory control theory was devised to help answer questions about the common content of political and religious belief. It sought to shed light on why people are so often drawn to structure and external sources of order and control, and to then use this understanding as a means for explaining the allure of particular types of religious and political beliefs (Kay et al., 2008). The (very basic) gist of CCT is that an oft-overlooked reason why people care about personal control is that it satisfies the higher-order goal of believing in a non-random, non-chaotic, structured, and orderly social world. Randomness and chaos are aversive and threatening feelings, and perception of personal control represent an ideal way to shield the self from these cognitions: if whatever happens to someone, whether good or bad, is the result of that person's actions, then the world is orderly insofar as there exists a clear, observable cause-and-effect to important outcomes. But perceptions of personal control and people's drive to achieve them vary greatly, within individuals and across individuals, within cultures and across cultures, and as a function of immediate situational constraints. How, then, do people maintain consistent beliefs in order and structure in the face of these fluctuations in feelings of personal control? According to CCT, within the context of the motive to believe in an orderly and structured world, there exists a psychological substitutability between cognitions about the self and cognitions about the external world. Endorsing external systems - whether they be one's government, an interventionist God, or even basic notions of epistemic structure-can serve an overlapping psychological function with beliefs in personal control; both of these types of beliefs imply a world in which events do not happen randomly or haphazardly. Thus, for the purposes of maintaining a view of the world as orderly and structured, these two types of beliefs - about the self and about the external worldshould be psychologically substitutable with one another, both capable of making the world appear non-random and ordered. The offshoot of this is that many seemingly diverse worldviews can be connected by their common connection to personal control compensation and the pursuit of order and structure. 
Much of the initial wave of CCT research sought to demonstrate this by connecting personal control motivations to specific types of religious and political beliefs. It also focused on delineating the moderators and mediators of CCT effects, teasing it apart from related theories and examining the presumed mechanisms (for reviews of most of this first wave of work, see (Kay et al., 2009; Landau et al., 2015). The dependent measures in these studies centered on "big" issues (e.g., belief in god), but their direct connection to issues of social justice-inequality, prejudice, stereotyping, morality and ethics - was opaque at best. The theory was devised to explain sweeping trends in political and religious belief, and that is what the research focused on.

But, slowly, this changed. In a 2014 piece, Justin Friesen and his colleagues used CCT to understand people's proclivity towards organizing in and endorsing hierarchies despite explicit ideologies preaching the fairness of equality (Friesen et al., 2014). This was one of the first attempts at applying the underlying ideas to something more akin to a social issue or social problem. And from there, many studies followed. Compensatory control theory has been used as the key explanatory lever in papers covering, for example: gender stereotyping (Ma et al., 2019), social progress (Rujtens et al., Rutjens, van der Pligt, et al., 2010; Rutjens, van Harreveld, et al., 2010), morality (Stanley et al., 2020), science denial (Rutjens, van der Pligt, et al., 2010; Rutjens, van Harreveld, et al., 2010; Rujtens et al., 2013), system justification (Knight et al., 2014; Whitson et al., 2015), extremism (Kay \& Eibach, 2013; Mirisola et al., 2014), leadership preferences (Kakkar \& Sivanthan, 2017), prejudice (Greenaway et al., 2014), meritocracy (Goode et al., 2014), gun policies (Shepherd \& Kay, 2018), antisemitism (Kofta et al., 2020), acceptance of Covid-19 interventions (Wnuk et al., 2020), fake news belief (Axt et al., 2020), organizational trust (Huang \& Whitson, 2020), and even nuclear policy (Anderson \& Reedy, 2019). In short, then, despite its initial restricted emphasis, CCT has been employed to help understand a wide range of societally relevant issues, many of which are central to social justice.

Working on CCT has also led to us to new contexts within which to study social justice. The equitable employment of military veterans is a social justice issue that has received very little attention in basic social psychology journals. We (the first author, along with David Sherman, a social psychologist at University of California Santa Barbara) have launched a new initiative (called the Veteran Transition Research Initiative, and housed at Duke University) aimed at understanding and ameliorating the experience of military veterans transitioning to civilian workplaces. The military is a fascinating context with which to study control because it is a "total institution" that asks its members to adopt its values, norms, and practices (McGarry et al., 2015; Moore, 2017). The military provides a significant degree of structure, order, and reliability to its members, a level of environmental structure that is in sharp contrast to less structured civilian environments (Shepherd et al., 2021). In ongoing research conducted with transitioning military veterans, we have sought to expand CCT by exploring the consequences of having external sources of control become a substantial method of satisfying a person's pursuit of order and structure. For people immersed in a dependable environment of rigid order and hierarchy, it is possible that this structured environment is a central method of satisfying their need for structure. This raises a novel theoretical 
question: If aspects of one's environment can reliably satisfy one's pursuit of order and structure, does this alleviate the need of personal control to satisfy these pursuits? The military exemplifies this kind of dependably structured environment. As such, during military service, people may develop a level of reliance on environmental structure to satisfy their need for order. After military service, then, the veterans transition to an environment that provides much less structure and order. The question being explored then is how are transitioning veterans impacted by losing the amount of structure provided by their environment after leaving military service? One preliminary finding is that perceived structure at one's first post military job predicts both feelings of efficacy and belonging (Gibbs et al., 2020). We raise this line of work here because it nicely illustrates an important point: not only can basic theory help inform applied issues, but transporting basic theory to new applied contexts can help inform and refine the theory itself (Wiesenfeld \& Brockner, 2012). That is, using CCT to understand the military to civilian transition experience not only has the potential to inform efforts to aid military veterans in their transition to the workplace by identifying social psychological factors for intervention (see Shepherd et al., 2021 for discussion) but it also allows for the extension of CCT in several theoretical directions which we are currently exploring.

Nearly 60 years ago, Kurt Lewin (1943) noted that "there is nothing as practical as a good theory." We suggest here that this is true in more ways than one: that is, that theory can help address practical problems for both society and for researchers. The pursuit of basic theoretical questions, over time and in the lab, can lead to broadly applicable insights and new ways of looking at social problems. There is no question about that. At the same time, though, theory is also a practical means for researchers to find stimulation and balance in their career. As someone who was drawn to the field because of his interest (in roughly equal parts) in both social justice and social cognition, the first author spent a big proportion of his $\mathrm{PhD}$ and early career figuring out where his interest lay and what level of analysis to focus on. Diving into theory development has provided the opportunity to resolve this question without being forced to sacrifice one or the other, and to make explicit the connection between more basic and applied research projects.

\section{Declarations}

Conflict of interest The authors have no conflicts of interest to report.

Human and animal rights No novel research with human participants or animal subjects was reported here, only a review of previously published work.

\section{References}

Anderson, C., \& Reedy, J. (2019). Compensatory control theory and public opinion on nuclear policy: Developing an experimental measure in an applied environmental context. Frontiers in Communication, 4. https://doi.org/10.3389/fcomm.2019.00027

Axt, J. R., Landau, M. J., \& Kay, A. C. (2020). The psychological appeal of fake-news attributions. Psychological Science., 31(7), 848-857. 
Friesen, J. P., Kay, A. C., Eibach, R. P., \& Galinsky, A. D. (2014). Seeking structure in social organization: Compensatory control and the psychological advantage of hierarchy. Journal of Personality and Social Psychology, 106, 590-609.

Gibbs, W. C., Sherman, D. K., Ortosky, L., \& Kay, A. C. (2020, February). Veterans' belonging at work: The relationship between perceived structural difference and veterans' transition to the civilian workforce. In Poster presented at the society of personality \& social psychology self \& identity pre-conference.

Greenaway, K. H., Louis, W. R., Hornsey, M. J., \& Jones, J. M. (2014). Perceived control qualifies the effects of threat on prejudice. British Journal of Social Psychology, 53, 422-442.

Jost, J. T., \& Banaji, M. R. (1994). The role of stereotyping in system-justification and the production of false consciousness. British Journal of Social Psychology, 33(1), 1-27.

Kakkar, H., \& Sivanathan, N. (2017). When the appeal of a dominant leader is greater than a prestige leader. PNAS Proceedings of the National Academy of Sciences of the United States of America, 114(26), 6734-6739.

Kay, A. C., \& Eibach, R. D. (2013). Compensatory control and its implications for ideological extremism. Journal of Social Issues, 69, 564-585.

Kay, A. C., Gaucher, D., Napier, J. L., Callan, M. J., \& Laurin, K. (2008). God and the government: Testing a compensatory control mechanism for the support of external systems. Journal of Personality and Social Psychology, 95, 18-35.

Kay, A. C., Whitson, J., Gaucher, D., \& Galinsky, A. D. (2009). Compensatory control: In the mind, in our institutions, in the heavens. Current Directions in Psychological Science, 18, 264-268.

Knight, C. G., Tobin, S. J., \& Hornsey, M. J. (2014). From fighting the system to embracing it: Control loss promotes system justification among those high in psychological reactance. Journal of Experimental Social Psychology, 54, 139-146.

Kofta, M., Soral, W., \& Bilewicz, M. (2020). What breeds conspiracy antisemitism? The role of political uncontrollability and uncertainty in the belief in Jewish conspiracy. Journal of Personality and Social Psychology, 118(5), 900-918.

Landau, M. J., Kay, A. C., \& Whitson, J. (2015). Compensatory control and the appeal of a structured world. Psychological Bulletin, 141, 694-722.

Lerner, M. J. (1980). The belief in a just world. Springer.

Lewin, K. (1943). Psychology and the process of group living. Journal of Social Psychology, 17, $113-131$.

Ma, A., Axt, J., \& Kay, A. C. (2019). A control-based account of stereotyping. Journal of Experimental Social Psychology, 84, 103819.

McGarry, R., Walklate, S., \& Mythen, G. (2015). A sociological analysis of military resilience: Opening up the debate. Armed Forces \&amp; Society, 41, 352-378.

Mirisola, A., Roccato, M., Russo, S., Spagna, G., \& Vieno, A. (2014). Threat, compensatory control, and RWA. Political Psychology, 35, 795-812.

Moore, E. (2017). Grateful nation: Student veterans and the rise of the military-friendly campus. Duke University Press.

Rutjens, B. T., van der Pligt, J., \& van Harreveld, F. (2010). Deus or Darwin: Randomness and belief in theories about the origin of life. Journal of Experimental Social Psychology, 46, 1078-1080.

Rutjens, B. T., van Harreveld, F., \& van der Pligt, J. (2010). Yes we can: Belief in progress as compensatory control. Social Psychological and Personality Science, 1, 246-252.

Rutjens, B. T., van Harreveld, F., \& van der Pligt, J. (2013). Step by step: Finding compensatory order in science. Current Directions in Psychological Science, 22, 250-255.

Shepherd, S., Sherman, D. K., MacLean, A., \& Kay, A. C. (2021). The challenges of military veterans in their transition to the workplace: A call for integrating basic and applied psychological science. Perspectives on Psychological Science, 16(3), 1-24.

Sherman, D. K., Hartson, K. A., Binning, K. R., Purdie-Vaughns, V., Garcia, J., Taborsky-Barba, S., \& Cohen, G. L. (2013). Deflecting the trajectory and changing the narrative: How self-affirmation affects academic performance and motivation under identity threat. Journal of Personality and Social Psychology, 104(4), 591.

Steele, C. M. (1997). A threat in the air: How stereotypes shape intellectual identity and performance. American Psychologist, 52(6), 613-629.

Wiesenfeld, B. M., \& Brockner, J. (2012). On the reciprocal relationship between basic and applied psychological theory. Organizational Psychology Review, 2(2), 172-182. 
Whitson, J., Galinsky, A. G., \& Kay, A. C. (2015). The emotional roots of conspiratorial perceptions, system justification, and paranormal belief. Journal of Experimental Social Psychology, 56, 89-95.

Wnuk, A., Oleksy, T., \& Maison, D. (2020). The acceptance of Covid-19 tracking technologies: The role of perceived threat, lack of control, and ideological beliefs. PLOS ONE, 15(9), e0238973.

Publisher's Note Springer Nature remains neutral with regard to jurisdictional claims in published maps and institutional affiliations. 